\title{
Mathematics as a Complex System: Learning in Complex Adaptive Systems
}

\author{
A Response to Elizabeth Mowat \& Brent Davis
}

\author{
MICHELLE E. JORDAN \\ University of Texas at Austin (USA)
}

Some conceptions of knowledge invite the emergence of new worlds and the exploration of possible futures rather than attempt to reinforce stabilization and replication (Allen \& Vargas, 2007; Osberg, Biesta, \& Cilliers, 2008). The model by Mowat and Davis (2010) of mathematics as a "complex unity" makes such an invitation. If mathematics is a complex network of concepts linked by metaphors, then the understanding of mathematics needed by mathematicians, scientists, engineers, and students at all levels is not one of stationary concepts related in sequentially static order leading to the construction of a tower of mathematics, but a relational understanding of mathematics that privileges the dynamic interdependencies among and between mathematical concepts and metaphors and emphasizes the ways that boundaries connect as well as separate (Cilliers, 2001).

Adoption of such a model could facilitate new understandings not only of what mathematics is, but also of what it means to learn mathematics. A tower is built sequentially step-by-step, brick by concrete, definite, solid brick; a brick is either locked in place or it is not, learning has either occurred or it has not occurred. But a network of mathematics, where concepts depend on the strength of multiple metaphors of differing weights and on their relationships to other concepts enables a conception of learning as an ambiguous and heterogeneous process in which concepts come in and out of focus and knowledge shifts between smoke-like and crystal-like organization (Taylor \& Van Every, 2000). Learners need to expect learning experiences to proceed in non-linear fits and starts, for activities to be evolving and structuring, not pre-structured, and for 
"components of the system [to] never quite lock into place yet never quite dissolve into turbulence either" (Waldrop, 1991, p. 293). In short, learning mathematics has sources of irreducible uncertainty. Mowat and Davis's model of a mathematical network is useful in clarifying and helping us live with some of those uncertainties.

\section{Defining the System of Interest}

Mowat and Davis define their system of interest to be the complex unity of mathematics that emerges from the interaction of elements called concepts that are linked through conceptual metaphors. Although I was intrigued by and happy with this definition, I also appreciated the authors' acknowledgement of its limitations. Deciding the level of analysis at which one will observe a complex system and defining the elements and boundaries of that system are difficult and interesting issues whether one is concerned with the system's spatial or temporal aspects (Lemke, 2000; Wilensky \& Resnick, 1999). Complications in defining a system under study arise for reasons that Mowat and Davis allude to: complex systems function simultaneously at multiple scales of organization and these maco- and micro-levels are reciprocally influencing (Hruby, 2008); complex systems are not composed of cleanly nested hierarchical levels, rather levels are interpenetrating and overlapping, making it difficult to describe a system accurately in terms of superior and subordinate levels (Osberg, Biesta, \& Cilliers, 2008). Furthermore, complex systems are open to and interact with their environment, which includes other complex systems. Mutual influence can be enacted not only by hierarchically linked systems, but also between systems at parallel levels. Interacting systems can be constituted by the same elements and actions that play different roles depending on which system one wishes to consider (e.g., agent in one, environment in another). Finally, systems' structures and processes shift and transform over time (Mitchell, 2006).

The situation is further complicated for those of us who study human systems because human beings interact with our own constructions, our inventions, ideas and tools. It is difficult to decide what role different entities should take in our models of such systems. In my own work, I tend to take a classroom collective as the system of interest, one of the middle nested layers of Mowat and Davis's Figure 1 (p. 8), and I too struggle with defining the system of interest. For instance, when attempting to use complex adaptive systems theory to understand learning from classroom computermediated discourse about language and literacy (Jordan et al., 2007) my co-authors and I wrestled with issues such as the following: What are the learning entities that interact and self organize to create emergent patterns and properties? Is it the individual human participants or their ideas that are interacting? Although the interaction of written messages seems most prominent in our analysis, is this an artifact of the fact that the discussions were written and therefore reified? What elements of the system are changed over time? Messages are static once written, yet, through the interaction of messages emerges a conversation, and this may be regardless of who sent any particular message. 
Because our interest is ultimately always in student learning, collectively and individually, we eventually elected to imbue students/conversational participants with the title, agent. However, that choice, as Mowat and Davis described their choice, is not without problems. For example, one of the things that emerges from classroom interaction is a conversation. Conversation as an emergent property does not map onto "individual students" as agents as cleanly as "ants" maps to "colony" or as "cars" to "traffic jams". So too we would have been discontented with defining agents as messages or ideas, because agents in complex adaptive systems learn from feedback from their environment and from other agents and we were not sure how this could happen for messages or ideas. ${ }^{1}$

Today I find it helpful to differentiate between complex systems and complex adaptive systems. Human creations (e.g., mathematical networks) can be complex systems but they may not be complex adaptive systems because only social entities learn, adapting their future behavior based on feedback they receive from interactions. Adaptations then feed back into the system and influence subsequent evolution. The complexity of human creations is dependent on social interactions that occur in human complex adaptive systems operating simultaneously at many levels (e.g., individuals, families, work groups, classrooms, schools, societies). Therefore, if we want to understand mathematics as a complex system we need to attend also to the human complex adaptive systems from which complex unities of mathematics arise. Mathematics emerges largely through conversation, conversation being a primary process through which human agents interact with one another, with our natural and social environment, and with our emergent creations. We - teachers, students, engineers, scientists, etc. - create mathematical networks through our talk. Mowat and Davis alluded to this several times through their examples of mathematicians' talk.

Taking the classroom collective as their unit of analysis, Strom, Kemeny, Lehrer, and Forman (2001) used network analytic techniques to explore the development and structure of mathematical argument about the concept of measuring area as it emerged from the interactions of a group of second grade students and their teacher over the course of a 50-minute lesson. Students attempted to resolve contesting claims about the relative amount of space covered by three rectangles. Their conversation was contextualized by a prior activity in which the class had explored geometrical shapes and transformations while designing quilts.

Whereas Mowat and Davis conceptualized mathematics as a network of concepts linked by metaphors, Strom et al. (2001) attempted to capture "how various senses of mathematics - as imagined, as performed, and as historically rooted - were interrelated" (p. 733), The authors identified five concepts of area measure, thirteen procedures related to area measure, and four references made to the class's history with quilt designing that occurred at least once over the course of the lesson. Placing concepts,

\footnotetext{
${ }^{1}$ However, Scardamalia and Bereiter (2006) asserted that conceptual development requires "selforganization at the level of ideas." "New conceptual structures... emerge through the interaction of simpler elements that do not singly or in combination represent the new concept" (p. 103).
} 
procedures, and references to history around a circle and numbering the directed edges of the graph to indicate the temporal sequence of the codes, the authors created a visual representation of how these nodes were linked across time through conversational turns. Converting their representation from a directed graph to a matrix model, Strom et al. computed indices of the degree of connectivity between concepts, procedures and histories. They computed the centrality of each node, identifying, in effect, predominant concepts, procedures, and "prior histories" of the emergent argument, which they called landmarks or attractors, what Mowat and Davis might call hubs. One can imagine a similar analysis in which metaphors are used to link mathematical concepts to create a collective mathematical structure through shared discourse.

A difficulty with using network analysis to represent complex systems is that network analysis techniques are better at representing structures and properties than they are at representing dynamics of processes (e.g., how nodes and links propagate, receive, and process information) (Mitchell, 2006). Complexity science leads us to emphasize process as the phenomenon of interest. Therefore, complexivists using network analysis need to be careful not to get overcommitted to the concept of structure that may get in the way of a rich understanding of the role of time in the development of the mathematical understanding. By tracing the unfolding construction of a mathematical network, Strom et al. studied process, describing the dynamic evolution of a system and looking for identifiable patterns of interaction. At the same time as the internal structure of a mathematical argument was made visible through the authors' directed network graph, so too were the moment-by-moment dynamics of the argument, how the argument itself changed and also how the relationships among and between concepts, procedures, and history changed. An analysis such as that conducted by Strom et al., when coupled with our knowledge of the affordances and hindrances of particular metaphors that inhibit and facilitate understanding of particular mathematical concepts (e.g., Oehrtman 2009; Grant \& Nathan, 2008) might help us do the mapping of conceptual metaphors linking mathematical domains that Mowat and Davis suggest is necessary and also a mapping of the processes by which students' networks come into being, increase in robustness, and cascade into fragmentation and failure.

\section{Classroom Conversation as a Catalyst for Learning}

Just as it is important for researchers to be clear about how they are defining a system, so it is important for teachers to be clear not only about how they are defining subjects for study (e.g., mathematics) but also how they are defining students and classroom collectives. Mowat and Davis addressed the need for teachers to understand mathematics as a network of concepts linked by metaphors. They focused on how teachers could utilize knowledge of the network structure of mathematics in their interactions with students to support robust understandings of mathematics by connecting experiences (e.g., add links between clusters of nodes, introduce multiple metaphors, carefully select familiar source domains). In order to utilize the sophisticated framework and suggestions by Mowat and Davis in their intentional interactions with 
students, teachers need to develop understandings not only of the nature of mathematics as complex systems, but also of classroom collectives as complex adaptive systems.

It may do little good for teachers to conceptualize mathematics as a network if they think of that network as an expanding system in which metaphors are permanent rigid links between tightly bounded, closed concepts rather than thinking of a network as a dynamic emerging system of flexible metaphors linking permeable, fluctuating concepts, a system changing internally as well as growing outward. Likewise, if teachers take a mechanistic view of students individually and collectively, they are likely to miss the fact that mathematical networks are human-created tools emerging from the interaction of human beings in situated, unique contexts (Allen \& Vargas, 2007). Because complex adaptive systems are generative, relational, and uncertain in their unfolding, teachers adopting a complexity view of classroom collectives will find it helpful to attend to classroom conversation as a lever for improving students' mathematical understanding.

Individual and collective learning are mutually and reciprocally influencing through interactions among connected, diverse agents. In human systems, those interactions occur largely through conversation, on which the generation and evolution of both collective and individual mathematical networks are dependent. Talk is a way of building linkages and making sense out of experiences and sets of experiences. Scardamalia and Bereiter (2006) wrote that "All understandings are inventions; inventions are emergent" (p.103). Ideas emerge during discussion; they are not simply transmitted, even if the understandings that emerge in a classroom collective are the same as or very similar to what others have already thought. Rather than serving primarily as a vehicle for sharing knowledge and critiquing ideas, conversation plays an active role in idea creation and idea improvement, particularly when conversation is oriented toward cooperative understanding. Conversation about mathematics should be a platform for further learning; knowing in order to learn, rather than learning in order to know.

Mathematical understanding at the collective level is not simply an aggregate of individual mental states; nor is collective knowledge simply transferable to individual learners. "Cultural artifacts that become part of the "inside" of a person are much different than those artifacts as they existed "outside" the person... as the culture becomes internalized, persons change" (Ricca, 2009, p. 59). When a student hears herself explain an idea to others, it is possible and perhaps even likely that her thinking will be changed, reflected back on itself as the child juxtaposes her own explorations against the explorations of others (Stroup, Ares, \& Hurford, 2005). Classroom conversation enables reflection at collective and at individual levels (Cobb et al., 1997) and reflection at both of these levels can prompt learning and metacognitive awareness by students of their individual and collective mathematical networks and of the dynamic processes by which those networks are unfolding. Explicit and periodic reflection on locally-emerging mathematical networks themselves may be particularly facilitative of learning.

There is evidence that peer interactions can be more generative than teacher-student interactions during classroom conversation involving mathematics and other academic 
subjects ${ }^{2}$ (e.g., Almasi, O'Flahavan, \& Arya, 2001; Baker-Sennett, Matusov, \& Rogoff, 2008; Kapur, 2008; Nystrand, Wu, \& Gamoran, 2003). However, peer interactions are a historically undervalued and under-utilized resource in classrooms, and "an adequate theory of learning through social interaction, of how to make use of personal reciprocal relationships is still lacking" (Mainzer, 2009, p. 24). From a complexity perspective, the power of peer interaction lies in the micro-diversity among students because diversity is required for a system to generate creative responses to a changing environment. For instance, if all conceptual metaphors come through the teacher, mathematical concepts will likely be impoverished and the robustness of mathematical networks lessened at individual and collective levels of understanding. However, the effects of student heterogeneity should be carefully observed as they can be quite different in different contexts, for example, sometimes heterogeneity leads to system stability and at other times it has a catalyzing, cascading effect (Miller \& Page, 2007). Additionally, peer interactions do not necessarily lead to immediate returns; for example, interactions facilitative of improved individual learning can appear to produce failure at the collective level (Kapur, 2008).

Consideration needs to be given not only to whether students are interacting, but also to how classroom structures constrain and enable the quality of their interactions and the ways it is possible for them to interact. How classroom collectives are structured may influence the boundaries and constraints of what can occur (Miller \& Page, 2007). Network analysis (and other complexity-inspired models) might help us consider what different classroom network structures afford in terms of possible functions students could fulfill or create for themselves collectively and individually as they engage in knowledge building about mathematical networks of conceptual nodes linked through conceptual metaphors.

\section{References}

Allen, A. M., and L. Varga. (2007). Complexity: The co-evolution of epistemology, axiology and ontology. Nonlinear Dynamics, Psychology, and Life Sciences, 11 (1): 19-50.

Almasi, J., J. O'Flahavan, and P. Arya. (2001). A comparative analysis of student and teacher development in more and less proficient discussions of literature. Reading Research Quarterly, 36 (2): 96-120.

Baker-Sennett, J., E. Matusov, and B. Rogoff. (2008). Children's planning of classroom plays with adult or child direction. Social Development, 17 (4): 998-1018.

Cilliers, P. (2001). Boundaries, hierarchies and networks in complex systems. International Journal of Innovation Management, 5 (2): 135-147.

Cobb, P., A. Boufi, K. McClain, and J. Whitenack. (1997). Reflective discourse and collective reflection. Journal for Research in Mathematics Education, 28 (3): 258-277.

Grant, T. S., and M. J. Nathan, (2008). Students' conceptual metaphors influence their statistical reasoning about confidence intervals (WCER Working Paper No. 2008-5). Madison: University of

\footnotetext{
2 This does not mean that teacher participation is not important. For instance, in the Strom et al. (2001) article referenced above, the authors conducted a parallel analysis of functions the teacher enacted through her participation in the conversation. The teacher is also an important source of diversity in classroom collectives.
} 
Wisconsin-Madison, Wisconsin Center for Education Research. Retrieved November 20, 2009 from http://www.wcer.wisc.edu/publications/workingPapers/papers.php

Hruby, G. (2008). Grounding reading comprehension theory in the neuroscience literatures. In Handbook of research on reading comprehension, edited by G. Duffy and S. Israel, 189-223. London: Lawrence Erlbaum Associates Taylor and Francis Group.

Jordan, M., D. L. Schallert, A. Cheng, Y. Park, H. Lee, Y. Chen, M. Yang, R. Chu, and Y. Chang. (2007). Self-organization in classroom computer-mediated discussion through a complex adaptive systems lens. National Reading Conference Yearbook, 56: 39-53.

Kapur, M. (2008). Productive failure. Cognition and Instruction, 26(3): 379-425.

Lemke, J. L. (2000). Across the scales of time: Artifacts, activities, and meanings in ecosocial systems. Mind, Culture and Activity, 7 (4): 273-290.

Mainzer, K. (2009). Thinking in complexity: A new paradigm for learning. Complicity, 6 (1): 23-27.

Miller, J. H., and S. E. Page. (2007). Complex adaptive systems: An introduction to computational models of social life. Princeton, NJ: Princeton University Press.

Mitchell, M. (2006). Complex systems: Network thinking. Artificial Intelligence, 170(18): 1194-1212.

Nystrand, M., L. L. Wu, and A. Gamoran. (2003). Questions in time: Investigating the structure and dynamics of unfolding classroom discourse. Discourse processes, 35(2): 135-198.

Oehrtman, M. (2009). Collapsing dimensions, physical limitation, and other student metaphors for limit concepts. Journal for Research in Mathematics Education, 40(4): 396-426.

Osberg, D., G. Biesta, and P. Cilliers. (2008). From representation to emergence: Complexity's challenge to the epistemology of schooling. Educational Philosophy and Theory, 40 (1): 213-227.

Ricca, B. 2009. The imposition of boundaries. Complicity, (6) 1: 56-60.

Scardamalia, M., and C. Bereiter. (2006). Knowledge building: Theory, pedagogy, and technology. In Cambridge handbook of the learning sciences, edited by K. Sawyer, 97-118. New York: Cambridge University Press.

Strom, D., V. Kemeny, R. Lehrer, and E. Forman. (2001). Visualizing the emergent structure of children's mathematical argument. Cognitive Science, 25: 733-773.

Stroup, W. M., N. M. Ares, and A. C. Hurford. (2005). A dialectic analysis of generativity: Issues of network-supported design in mathematics and science. Mathematical Thinking and Learning, 7(3): 181-206.

Taylor, J. R., and E. J. Van Every. (2000). The emergent organization: Communication as its site and surface. Mahwah, NJ: Erlbaum.

Waldrop, M. M. (1991). Complexity: The emerging science at the edge of order and chaos. New York: Simon and Schuster.

Wilensky, U. and M. Resnick. (1999). Thinking in levels: A dynamic systems approach to making sense of the world. Journal of Science Education and Technology, 8(1): 3-19.

\section{About the Author}

Michelle E. Jordan is a PhD candidate at the University of Texas at Austin in the Department of Educational Psychology. She has been thinking and writing about applications of complex adaptive systems theory to issues of learning for several years, finding this framework helpful when she was an elementary school music teacher and now as a scholar. Her PhD dissertation is entitled, Managing Uncertainty Through Peer Discourse During Collaborative Robotics Design Tasks in Upper Elementary School Settings. She can be contacted at [email: mejordan@mail.utexas.edu].

(C) Copyright 2010. The author, MICHELLE E. JORDAN assigns to the University of Alberta and other educational and non-profit institutions a non-exclusive license to use this document for personal use and in courses of instruction provided that the article is used in full and this copyright statement is reproduced. The author also grants a non-exclusive license to the University of Alberta to publish this document in full on the World Wide Web, and for the document to be published on mirrors on the World Wide Web. Any other usage is prohibited without the express permission of the authors. 